\title{
A nested-PCR with an Internal Amplification Control for the detection and differentiation of Bartonella henselae and $B$. clarridgeiae: An examination of cats in Trinidad Joanne N Rampersad ${ }^{1}$, John D Watkins², Michael S Samlal2, Raymond Deonanan ${ }^{2}$, Shalini Ramsubeik ${ }^{2}$ and David R Ammons*2
}

Address: ${ }^{1}$ Dept. of Life Sciences, The University of the West Indies, St. Augustine, Trinidad, Trinidad and Tobago and ${ }^{2}$ School of Veterinary Medicine, The University of the West Indies, Eric Williams Medical Sciences Complex, Mt. Hope, Trinidad, Trinidad and Tobago

Email: Joanne N Rampersad - uwimdl@hotmail.com; John D Watkins - jdw4111@netscape.net; Michael S Samlal - sannandan@yahoo.co.uk; Raymond Deonanan - rdeo@tstt.net.tt; Shalini Ramsubeik - shalini36@hotmail.com; David R Ammons* - ammonstt@hotmail.com

* Corresponding author

Published: 12 August 2005

BMC Infectious Diseases 2005, 5:63 doi:10.1 186/147/-2334-5-63

This article is available from: http://www.biomedcentral.com/l47I-2334/5/63

(c) 2005 Rampersad et al; licensee BioMed Central Ltd.

This is an Open Access article distributed under the terms of the Creative Commons Attribution License (http://creativecommons.org/licenses/by/2.0), which permits unrestricted use, distribution, and reproduction in any medium, provided the original work is properly cited.

\begin{abstract}
Background: Bartonella species are bacterial blood parasites of animals capable of causing disease in both animals and man. Cat-Scratch Disease (CSD) in humans is caused mainly by Bartonella henselae and is acquired from the cat, which serves as a reservoir for the bacteria. A second species, B. clarridgeiae is also implicated in the disease. Diagnosis of Bartonellosis by culture requires a week or more of incubation on enriched media containing blood, and recovery is often complicated by faster growing contaminating bacteria and fungi. PCR has been explored as an alternative to culture for both the detection and species identification of Bartonella, however sensitivity problems have been reported and false negative reactions due to blood inhibitors have not generally been addressed in test design.
\end{abstract}

Methods: A novel, nested-PCR was designed for the detection of Bartonella henselae and $B$. clarridgeiae based on the strategy of targeting species-specific size differences in the I6S-23S rDNA intergenic regions. An Internal Amplification Control was used for detecting PCR inhibition. The nested-PCR was utilized in a study on 103 blood samples from pet and stray cats in Trinidad.

Results: None of the samples were positive by primary PCR, but the Nested-PCR detected Bartonella in $32 / 103(31 \%)$ cats where 16 were infected with only B. henselae, 13 with only $B$. clarridgeiae and 3 with both species. Of 22 stray cats housed at an animal shelter, $13(59 \%)$ were positive for either or both species, supporting the reported increased incidence of Bartonella among feral cats.

Conclusion: The usefulness of a single PCR for the detection of Bartonella henselae and $B$. clarridgeiae in the blood of cats is questionable. A nested-PCR offers increased sensitivity over a primary PCR and should be evaluated with currently used methods for the routine detection and speciation of Bartonella henselae and B. clarridgeiae. In Trinidad, B. henselae and B. clarridgeiae are the predominant species in cats and infection appears highest with stray cats, however $B$. clarridgeiae may be present at levels similar to that of $B$. henselae in the pet population. 


\section{Background}

Bartonella are fastidious, gram-negative, bacteria comprised of at least 19 species and 3 subspecies [1] that are obligate parasites of the blood in reservoir animals. Bartonella species are considered emerging zoonotic pathogens [2] and may be involved in a number of disease presentations including angiomatosis [3] and ocular manifestations [4]. Similarly, Bartonella species are being associated with disease in their animal hosts (see reviews [2,5]. The role of cats as a reservoir for human Bartonellosis is well documented however probably incomplete. Studies suggest that other Bartonella species, known to cause disease in humans, are found in the cat (see for example [6] and [7]. Of these, Bartonella henselae and, to a lesser extent, Bartonella clarridgeiae are known to cause Cat-Scratch Disease (CSD) in humans [8]; see also [9] for review of CSD.

As a fastidious organism, Bartonella usually requires over a week of incubation for primary isolation. The slow growth of the organism complicates its isolation since faster growing bacteria and fungi can overrun the plate. Thus various types of tests using Polymerase Chain Reaction (PCR) have been explored as a diagnostic tool for the detection and identification of Bartonella species from blood [10-12]. Previously, Jensen et al., [13] developed a PCR for the detection of Bartonella that targets species-specific size differences in the 16S-23S rDNA intergenic region. However, as a primary $\mathrm{PCR}$, it was questionable if the sensitivity of the test was optimal for the detection of relatively low numbers of bacteria [14] and a control for the detection of false-negative reactions due to inhibition by blood components was not addressed. Herein we describe the development of a nested-PCR for the detection of B. henselae and B. clarridgeiae based on the strategy of species-specific size differences in the 16S-23S rDNA intergenic region that includes an Internal Amplification Control for PCR inhibitors. The test was evaluated on the blood of 103 apparently healthy cats in Trinidad to investigate the presence of these organisms in the local cat population and to verify the test's ability to detect these organisms in the blood of apparently healthy animals.

\section{Methods \\ Specimen collection}

All samples were collected over an 11 month period in 2001. Blood samples were collected in commercial blood collection tubes containing EDTA and transported to the laboratory on ice, where possible the same day, or stored at $4{ }^{\circ} \mathrm{C}$ until transported. Samples were collected from geographically distinct areas in Trinidad including an animal shelter, private veterinary clinics and the Veterinary Hospital located at the University of the West Indies' School of Veterinary Medicine by both Veterinarians and final year veterinary students.

\section{PCR}

DNA was extracted from whole blood according to the method of Boom et al., [15] with modifications as described by Rampersad et al., [16]. One microlitre of blood-extracted DNA template was used in the primary PCR reaction and $1 \mu \mathrm{l}$ of the primary reaction was used in the nested reaction. In order to minimize contamination, separate rooms were used for preparing the PCR reaction mix, template preparation, gel electrophoresis, and performing nested reactions. Nested reactions were performed in a biosafety hood where $1 \mu$ l of primary reaction was delivered to a nested tube with a $1 \mu$ l urine loop, the end of the loop was then washed briefly in a $10 \%$ bleach solution, rinsed in water then flamed before reusing.

Primary and nested-PCR reactions were optimized by testing $1.5,2$ and $3 \mathrm{mM} \mathrm{MgCl}_{2}$ in the reaction, each at 12 temperatures ranging from $45^{\circ} \mathrm{C}$ to $65^{\circ} \mathrm{C}$ using an Eppendorf Gradient Master Cycler. B. henselae and B. clarridgeiae strains used for template were a gift from Dr. Jill Clarridge. Optimized PCR cycle conditions were $94^{\circ} \mathrm{C}-15 \mathrm{~s}, 48.2^{\circ} \mathrm{C}$ $-30 \mathrm{~s}$ and $72^{\circ} \mathrm{C}-30 \mathrm{~s}$ for 40 cycles for the primary-PCR and $94^{\circ} \mathrm{C}-15 \mathrm{~s}, 56^{\circ} \mathrm{C}-30 \mathrm{~s}$ and $72^{\circ} \mathrm{C}-30 \mathrm{~s}$ for 40 cycles for the nested-PCR. The PCR strategy was an adaptation of a primary PCR described by Jensen et al., [13]. Primary PCR primers were P-bhenfa (5'-TCTTCGTTTCTCTTTCTTCA) and P-benr1 (5'-CAAGCGCGCGCTCTAACC) which gave an approximately $186 \mathrm{bp}$ fragment for $B$. henselae and a 168 bp fragment for B. clarridgeiae, and nested primers $\mathrm{N}$ bhenfla (5'-GATGATCCCAAGCCTTCTGGC) and Nbhenr (5'-AACCAACTGAGCTACAAGCC) which gave an approximately $152 \mathrm{bp}$ fragment for $B$. henselae and a 134 bp fragment for $B$. clarridgeiae. The Internal Amplification Control (IAC) consisted of a DNA amplicon, randomly amplified from the genome of a chicken with primer IAC (5'-TGTTTGACAGCTTATCAT). All reactions were performed in a $25 \mu \mathrm{l}$ volume as follows: Primary reaction (0.2 mM each dNTP, 0.5 pmoles/ $\mu$ l each P-bhenfa and Pbenr1, $3 \mathrm{mM} \mathrm{MgCl}_{2}$ reaction buffer, 0.4 pmoles $/ \mu$ l primer IAC, $1 \mu \mathrm{l}$ of IAC template stock (concentration unknown), 0.5 units Taq polymerase (Promega) and Nested (0.2 mM each dNTP, 0.5 pmoles/ $\mu$ l each N-bhenf1a and N-bhenr, $1.5 \mathrm{mM} \mathrm{MgCl}_{2}$ reaction buffer, $0.4 \mathrm{pmoles} / \mu \mathrm{l}$ primer IAC, 0.5 units Taq polymerase).

The B. clarridgeiae-specific PCR was performed using $1 \mu \mathrm{l}$ of a primary reaction in a PCR reaction with primers bclarF (5'- GCACAAGCCTCTGAGAGGGA) and N-bhenr. Reactions were performed in a $25 \mu$ l volume as follows: Primary reaction $(0.2 \mathrm{mM}$ each $\mathrm{dNTP}, 0.5 \mathrm{pmoles} / \mu \mathrm{l}$ each primer, $3 \mathrm{mM} \mathrm{MgCl}_{2}$ reaction buffer, 0.5 units Taq polymerase). PCR cycle conditions were $94^{\circ} \mathrm{C}-15 \mathrm{~s}, 55^{\circ} \mathrm{C}$ $-30 \mathrm{~s}$ and $72{ }^{\circ} \mathrm{C}-30 \mathrm{~s}$ for 40 cycles. 


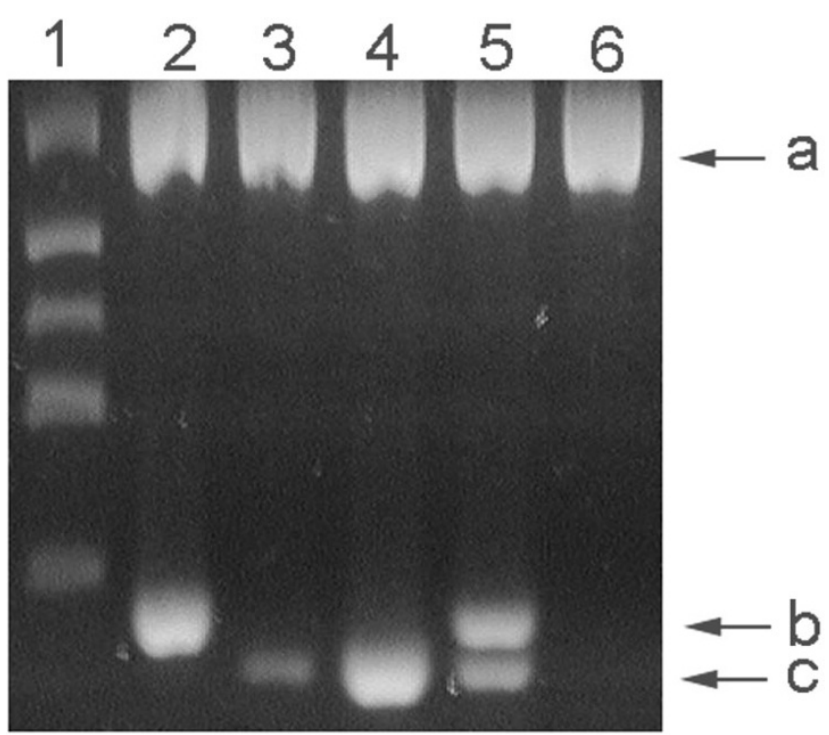

Figure I

PCR amplification products. A $3 \%$ agarose gel showing lane I) DNA size markers (bp) of 88I, 520, 337, $275 \mathrm{I}$ II and lanes 2-6) nested-PCR reactions of blood samples. Band a) internal amplification control, band $b$ ) $B$. henselae, and band $c$ ) B. clarridgeiae.

PCR amplification products were separated on either a $2 \%$ or 3\% agarose gel, stained with ethidium bromide and visualized under $302 \mathrm{~nm}$ ultra-violet light. DNA markers were created by PCR amplification of virulence genes from Escherichia coli generating calculated-sized fragments (bp) of 881, 520, 337, 275171 and relative sizes confirmed using a commercial DNA size standard (100 bp ladder, Promega).

\section{Culture}

One hundred microliters of blood was spread on a Brain Heart Infusion Agar plate (Difco) supplemented with $10 \%$ whole sheep blood and incubated for 2-3 weeks at $37^{\circ} \mathrm{C}$ in $5 \% \mathrm{CO}_{2}$. In some cases the blood was frozen at $70^{\circ} \mathrm{C}$ before being cultured.

\section{DNA sequencing}

Amplification products generated in the nested reaction for $B$. henselae and $B$. clarridgeiae were electrophoresed through a $1 \%$ agarose gel. The agarose containing the amplified DNA was cut from the gel, briefly frozen then thawed and spun at 12,000 rpm through a polypropylene fibre to remove the DNA-containing liquid. The DNA was concentrated by ethanol precipitation and used in the sequencing reaction. An ABI Big Dye sequencing kit was used according to manufacturer's instructions using the nested primers individually in two separate reactions, and the reactions resolved on an ABI 377 DNA sequencing machine.

\section{Results}

Of 103 blood samples subjected to PCR, none of the samples were positive for Bartonella in the primary reaction, but 32 were positive in the nested reaction. Inhibition was observed in 3 primary reactions indicated by a relatively light band seen for the IAC. However, one of these reactions was later positive for both $B$. henselae and $B$. clarridgeiae with the nested reaction. Two amplification bands of differing mobilities were observed in the nested reaction, both migrating below the 171 bp size marker (Figure $1)$. The larger fragment co-migrated with an amplification product generated from $B$. henselae (data not shown) and the smaller band was of a size expected from $B$. clarridgeiae. When the primary PCR reaction was used as template in a PCR reaction with a primer specific for $B$. clarridgeiae, only those samples that had the smaller sized fragment were positive. The identity of the respective amplification fragments were further investigated by DNA sequencing wherein the larger fragment was confirmed to be from B. henselae (GenBank: [DQ000494]) and the smaller-sized fragment from B. clarridgeiae (GenBank: [DQ003029]).

The number of Bartonella-negative samples along with those positive for either or both Bartonella species is given for both pet and stray animals in Table 1. Where the age of cats was known, infected cats (not including those from the shelter) ranged from 2-72 months. For stray cats at the animal shelter of unknown age, one half (11) of the cats were classified as adults and the other 11 as kittens, of which 6 of the 13 infected animals were adults and 7 kittens.

Blood cultures were generally contaminated with both spreading bacteria and fungi, to such a degree that it was felt that little meaningful data could be gained through culture, and it was discontinued.

\section{Discussion}

As an emerging pathogen known for causing disease in both humans and animals, a simple test for the routine identification of Bartonella species is desirable. Because multiple Bartonella species are associated with disease in both humans and animals, it would be advantageous to have a test capable of both detecting different species and differentiating between them. The strategy first presented by Jensen et al., [13] generally fits these requirements by targeting DNA-length heterogeneity in the 16S rDNA-23S rDNA intergenic region. As such, this test is well suited for the detection of $B$. henselae and B. clarridgeiae, the causative agents of CSD in humans. However, as a single PCR 
Table I: Bartonella species associated with living environments of cats

\begin{tabular}{|c|c|c|c|}
\hline & Pets & Animal shelter & Total \\
\hline B. henselae & 7 & 9 & 16 \\
\hline B. clarridgeiae & 10 & 3 & 13 \\
\hline Both species & 2 & I & 3 \\
\hline Bartonella negative & 62 & 9 & 71 \\
\hline Total & 81 & 22 & 103 \\
\hline
\end{tabular}

The number of Bartonella-negative samples along with those positive for either or both Bartonella species is given for both pet and stray animals.

reaction, this test has questionable sensitivity and has in fact been reported to show less sensitivity than culture for the detection of $B$. henselae and B. clarridgeiae in blood, [14]; see also [17]. Similarly, the primary reaction used in this study was unable to detect Bartonella DNA in any of the samples although we were able to show the presence of Bartonella DNA in 32 samples with a nested reaction. These results question the usefulness of a single PCR reaction for the detection of Bartonella in blood without further enhancing the overall sensitivity of the test, such as with the addition of a nested-PCR reaction. However, many laboratories are reluctant to use a nested reaction for fear that its high sensitivity will detect contaminating DNAs (mainly amplicons) and deliver a false-positive result. In this work, none of our negative controls were positive. To help control cross contamination, template preparation, assembly of the PCR reaction, nested reactions and gel electrophoresis were performed in different rooms. Especially useful was the use of a UV hood and a $1 \mu \mathrm{l}$ urine loop instead of barrier tips to transfer an aliquot of the primary reaction to the nested reaction. By immersing the end of the loop, after each transfer, in a $10 \%$ bleach solution to chemically degrade any amplicons, and then rinsing with water before flaming, any chance splattering or aerosolization of DNAs from the loop during flaming was reduced.

The test of Jensen et al., [13] also lacked an Internal Amplification Control (IAC) to detect PCR inhibition. In fact, arguments have been made for Internal Amplification Controls to be mandatory when describing diagnostic tests based on PCR [18]. Since blood, which is a known source of PCR inhibitors, is a commonly used sample for Bartonella detection, it is important that PCR-based tests for Bartonella include an IAC. Individuals interested in evaluating this method may write the authors for an aliquot of the IAC template.

Because of the slow growth and long culture time for Bartonella, faster growing contaminating bacteria and fungi can overrun a culture plate and make the detection of Bartonella difficult or even impossible. Early in this study we found that the contamination problem was so severe that culture was discontinued. The unexpectedly high level of contamination may have originated from the blood collection process where blood was collected by both private veterinary clinics and veterinary students as part of their studies, and thus was not strictly controlled. Although perhaps undesirable for the purposes of this study, the uncontrolled nature of its collection perhaps more accurately represented blood as it would arrive to the laboratory for diagnosis, and underscores one advantage of PCR over culture for the detection of Bartonella.

Prevalence studies reported for Bartonella infection in cats are generally characterized by a relatively high prevalence of $B$. henselae compared to B. clarridgeiae [19-22]. In this study, our results were mostly consistent with other studies where $B$. henselae was detected in slightly more samples than B. clarridgeiae. However approximately $40 \%$ of the infected cats originated from an animal shelter, which were not necessarily representative of the cat population as a whole in Trinidad. For example, discounting the animals from the shelter, 7 (8.6\%) animals were positive for B. henselae, 10 (12.3\%) for B. clarridgeiae and $2(2.5 \%)$ for both bacteria, suggesting that $B$. clarridgeiae may be found among pet cats at levels similar to, or even higher than that for $B$. henselae. As has been reported in other studies $[21,22]$, cases of mixed infections with both species were found. In addition, there was a clear relationship between cats expected to be exposed to fleas (e.g. stray cats at an animal shelter), and the prevalence of infection.

Although this test was designed for the detection of $B$. henselae and B. clarridgeiae, sequence homology between the primers and other Bartonella species indicates that this test might be useful for the detection of other Bartonella species (Figure 2). Of the 15 species for which sequence data was available, only three species, $B$. bovis, B. schoenbuchensis and B. birtlesii would not be expected to amplify due to a single base pair mismatch between the template and the terminal 3' position of the primer. Admittedly, our test would benefit from a redesign of the forward primers (Figure 2), so that they would recognize all 


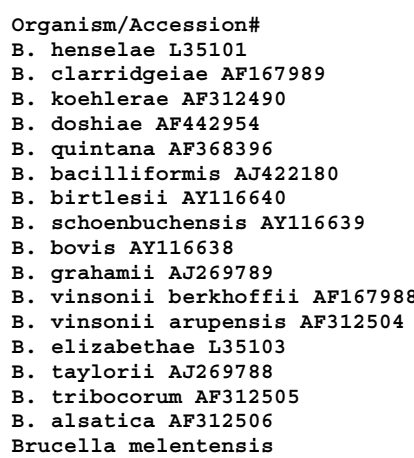

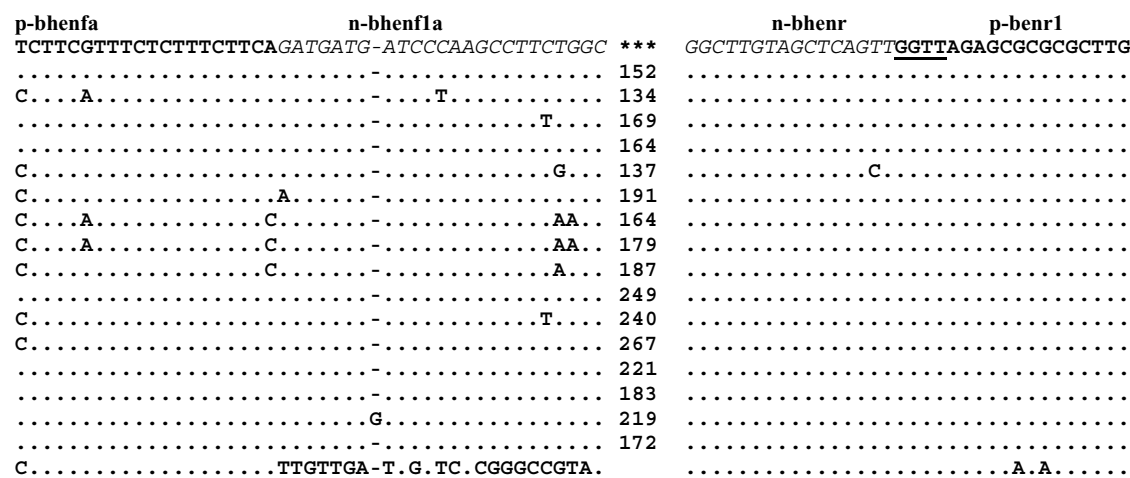

\section{Figure 2}

Primer and template sequence homology. Bacterial species are followed by their GenBank accession numbers. Primer sequences are given below the primer's name at the top, primary primers are in bold, nested primers are in italics and sequence shared by two primers is underlined. A dot (.) below each nucleotide in the primer represents homology at that position in each species' DNA with the primer and letter signifies the diverging nucleotide found in the bacteria DNA. A dash (-) represents spaces placed in the sequence for alignment purposes. Three asterisks (***) signifies the variable length region of DNA found between the forward and reverse primers and the number given at that site for each species indicates the size of the amplicons generated from the nested reaction.

known Bartonella species, [23]. Jensen et al., [13] had identified sequence homology in the 16S-23S rRNA intergenic region between Bartonella with Brucella species. In this test, sequence homology indicates that the primary PCR should amplify Brucella DNA, however no such amplification should occur in the nested reaction (Figure 2).

\section{Conclusion}

The usefulness of a single PCR for the detection of $B$. henselae and B. clarridgeiae in the blood of cats is questionable and enhancement methods, such as a nested-PCR, should be utilized. In Trinidad, B. henselae and B. clarridgeiae are found in cats and infection appears highest among stray cats, however $B$. clarridgeiae may be present at levels similar to, or higher than, that of $B$. henselae in pet cats.

\section{Competing interests}

The author(s) declare that they have no competing interests.

\section{Authors' contributions}

JNR and DRA provided project and diagnostic design/ development and performed diagnostics, JDW conceived the project and provided project design and management, MSS performed template preparation and sample management, RD and SR collected blood and information on the animals.

\section{Acknowledgements}

We thank Dr. Jill Clarridge for providing us with strains of $B$. henselae and $B$. clarridgeiae and her helpful suggestions on the culture of these organisms from blood, and the DNA Unit at Mt. Hope Trinidad for assistance with DNA sequencing. We also acknowledge the financial support provided to DRA by a grant from the University of the West Indies' Research and Publication Committee (Grant\# CRP.4Z).

\section{References}

I. List of Bacterial Names with Standing in Nomenclature Genus Bartonella [http://www.bacterio.cict.fr/b/bartonella.html]

2. Boulouis H, Chang C, Henn J, Dasten R, Chomel B: Factors associated with the rapid emergence of zoonotic Bartonella infections. Vet Res 2005, 36:383-410.

3. Santos R, Cardoso O, Rodrigues P, Cardoso J, Machado J, Afonso A, Bacellar F, Marston E, Proenca R: Bacillary angiomatosis by Bartonella quintana in an HIV-infected patient. J Am Acad Dermatol 2000, 42:299-30I.

4. Khurana RN, Albini T, Green RL, Rao NA, Lim Jl: Bartonella henselae infection presenting as a unilateral panuveitis simulating Vogt-Koyanagi-Harada syndrome. Am J Ophthalmol 2004, 138:1063-1065.

5. Breitschwerdt $E B$, Kordick DL: Bartonella infection in animals: Carriership, reservoir potential, pathogenicity, and zoonotic potential for human infection. Clin Microbiol Rev 2000, 13:428-438.

6. Hjelm E, McGill S, Blomqvist G: Prevalence of antibodies to Bartonella henselae, B. elizabethae and B. quintana in Swedish domestic cats. Scand J Infect Dis 2002, 34:192-196.

7. Aboudharam G, La VD, Davoust B, Drancourt M, Raoult D: Molecular detection of Bartonella spp. in the dental pulp of stray cats buried for a year. Microb Pathog 2005, 38:47-5I.

8. Kordick DL, Hilyard EJ, Hadfield TL, Wilson KH, Steigerwalt AG Brenner DJ, Breitschwerdt EB: Bartonella clarridgeiae, a newly recognized zoonotic pathogen causing inoculation papules, fever, and lymphadenopathy (Cat-Scratch Disease). J Clin Microbiol 1997, 35:1813-1818. 
9. Lamps LW, Scott MA: Cat-scratch disease historic, clinical, and pathologic perspectives. Am J Clin Pathol 2004, I 2 I (Suppl):S7I-80.

10. Del Prete R, Fumarola D, Ungari S, Fumarola L, Miragliotta G: Polymerase chain reaction detection of Bartonella henselae bacteraemia in an immunocompetent child with cat-scratch disease. Eur J Pediatr 2000, 159:356-359.

II. Avidor B, Graidy M, Efrat G, Leibowitz C, Shapira G, Schattner A, Zimhony O, Giladi M: Bartonella koehlerae, a new cat-associated agent of culture-negative human endocarditis. J Clin Microbiol 2004, 42:3462-3468.

12. Ciervo A, Ciceroni L: Rapid detection and differentiation of Bartonella spp. by a single-run real-time PCR. Mol Cell Probes 2004, I8:307-3।2.

13. Jensen WA, Fall MZ, Rooney J, Kordick DL, Breitshwerdt EB: Rapid Identification and differentiation of Bartonella species using a single-step PCR assay. J Clin Microbiol 2000, 38: 1717-1722.

14. Engvall EO, Fasth C, Brandstrom B, Fermer C, Blomqvist G, Englund $\mathrm{L}$ : Prevalence of Bartonella henselae in young, healthy cats in Sweden. Veterinary Record 2003, 152:366-369.

15. Boom R, Sol CJA, Salimans MMM, Jansen CL, Wertheim-van Dillen PME, Van der Noordaa J: Rapid and simple method for purification of nucleic acids. I Clin Microbiol 1990, 28:495-503.

16. Rampersad J, Cesar E, Campbell MD, Samlal M, Ammons D: A field evaluation of PCR for the routine detection of Babesia equi in horses. Vet Parasitol 2003, I | 4:8 I-87.

17. de Souza Zanutto M, Mamizuka EM, Raiz R Jr, de Lima TM, Diogo CL, Okay TS, Hagiwara MK: Experimental infection and horizontal transmission of Bartonella henselae in domestic cats. Rev Inst Med Trop Sao Paulo 200I, 43:257-26I.

18. Hoofar J, Cook N, Malorny, Wagner M, De Medici D, Abdulmawjood A, Fach P: Making Internal Amplification Control Mandatory for Diagnostic PCR. J Clin Microbiol 2003, 41:5835.

19. Rolain JM, Locatelli C, Chabanne L, Davoust B, Raoult D: Prevalence of Bartonella clarridgeiae and Bartonella henselae in domestic cats from France and detection of the organisms in erythrocytes by immunofluorescence. Clin Diagn Lab Immunol 2004, I I:423-425.

20. Heller R, Artois M, Xemar V, De Briel D, Gehin H, Jaulhac B, Monteil $\mathrm{H}$, Piemont Y: Prevalence of Bartonella henselae and Bartonella clarridgeiae in stray cats. J Clin Microbiol 1997, 35:I327-I33I.

21. Maruyama S, Sakai T, Morita Y, Tanaka S, Kabeya H, Boonmar S, Poapolathep A, Chalarmchaikit T, Chang CC, Kasten RW, Chomel $B B$, Katsube Y: Prevalence of Bartonella species and I6S rRNA gene types of Bartonella henselae from domestic cats in Thailand. Am J Trop Med Hyg 200I, 65:783-7.

22. Chomel BB, Carlos ET, Kasten RW, Yamamoto K, Chang CC, Carlos RS, Abenes MV, Pajares CM: Bartonella henselae and Bartonella clarridgeiae infection in domestic cats from The Philippines. Am J Trop Med Hyg 1999, 60:593-7.

23. Birtles RJ, Hazel S, Brown K, Raoult D, Begon M, Bennett M: Subtyping of uncultured bartonellae using sequence comparison of 16S/23S rRNA intergenic spacer regions amplified directly from infected blood. Mol Cell Probes 2000, 14:79-87.

\section{Pre-publication history}

The pre-publication history for this paper can be accessed here:

http://www.biomedcentral.com/1471-2334/5/63/prepub 